

October 2021

\title{
Raw Onions or a Raw Deal? The Straightforward Admission that Wasn't
}

Karl Enroth

University of Nebraska Medical Center

Tell us how you used this information in this short survey.

Follow this and additional works at: https://digitalcommons.unmc.edu/gmerj

Part of the Higher Education Commons, and the Medicine and Health Sciences Commons

\section{Recommended Citation}

Enroth, K. Raw Onions or a Raw Deal? The Straightforward Admission that Wasn't. Graduate Medical Education Research Journal. 2021 Oct 04; 3(1).

https://digitalcommons.unmc.edu/gmerj/vol3/iss1/40

This Conference Proceeding is brought to you for free and open access by DigitalCommons@UNMC. It has been accepted for inclusion in Graduate Medical Education Research Journal by an authorized editor of DigitalCommons@UNMC.For more information, please contact digitalcommons@unmc.edu. 


\section{Raw Onions or a Raw Deal? The Straightforward Admission that Wasn't}

Creative Commons License

(c) (i) ()

This work is licensed under a Creative Commons Attribution-Noncommercial-No Derivative Works 4.0 License. 


\section{SANDO Syndrome Associated with New POLG Heterozygous Gene Mutation: Case Report}

Daniel Crespo ${ }^{1}$, Deepmala Nandanwar ${ }^{1}$, Sachin Kedar ${ }^{1,2}$, Danish Bhatti ${ }^{1}$

${ }^{1}$ University of Nebraska Medical Center, College of Medicine, Department of Neurological Sciences ${ }^{2}$ University of Nebraska Medical Center, Truhlsen Eye Institute

Mentor: Sachin Kedar, Danish Bhatti

Program: Neurological Sciences

Type: Case Report

Background: Nuclear-encoded POLG gene encodes gamma subunit of the mitochondrial DNA polymerase that is responsible for replication of the mitochondrial DNA (mtDNA). Mutations of POLG gene can have multiple phenotypes including SANDO syndrome, first described in 1997. At the molecular level, A467T and W748S POLG mutations have been described in SANDO. The objective of this case report was to describe novel mutation of the DNA polymerase subunit gamma (POLG) gene with a phenotypic presentation of Sensory Ataxic Neuropathy, Dysarthria and Ophthalmoparesis Syndrome (SANDO).
Case: A 69-year-old female presented with two years of ophthalmoplegia, ataxia, falls, hoarseness and dysphagia. Her mother suffered from ataxia and falls. Exam showed multifocal dystonia, truncal ataxia with postural instability, appendicular ataxia, diffuse hyperreflexia, abnormal Hoffman, Babinski signs and frontal release signs. She had minimal rigidity and bradykinesia without tremors. Neuro-ophthalmological exam showed absence of both vertical and horizontal eye movements bilaterally, esotropia and right hypertropia and weak orbicularis oculi and oris weakness bilaterally. She had abnormalities of alternate trail marking, figure copying, and clock drawing indicating visuospatial and executive dysfunction. Workup including CSF, blood work and MRI Brain were unremarkable. Growth differentiation factor 15 levels were elevated suggesting a mitochondrial cytopathy Genetic evaluation revealed single nucleotide heterozygous gene mutation of the POLG gene (c.3614G $>$ C p.Gly1205Ala). This mutation has previously not been associated with pathology and hence felt to be of uncertain significance.

Conclusion: We report the phenotypic presentation of SANDO syndrome with a gene mutation previously classified as uncertain significance. Due to the clinical heterogeneity, overlapping phenotypes, diagnosis of mitochondrial diseases relies on the molecular detection of genetic mutations.

https://doi.org/10.32873/unmc.dc.gmerj.3.1.032

\section{Raw Onions or a Raw Deal? The Straightforward Admission that Wasn't Karl Enroth ${ }^{1}$}

${ }^{1}$ University of Nebraska Medical Center, College of Medicine, Department of Internal Medicine, Division of Pediatrics

\section{Mentor: Allison Ashford}

Program: Internal Medicine - Pediatrics

Type: Case Report

Case: An 11-year-old boy with a history of food allergies, moderate persistent asthma, and eczema was admitted after an allergic reaction. Earlier that day the patient had consumed lunch, including a chili dog with raw onions. The patient's father stated that the patient shouldn't have eaten raw onions as, "he is allergic to just about every raw food." After consuming lunch, the patient began "drooling" and became "uncomfortable." The patient was taken to the emergency department where he received epinephrine, methylprednisolone, and diphenhydramine. He was then admitted for observation.

The patient described a "pain" in his anterior neck. His exam was reassuring including bilateral clear lung fields. He was given a bottle of sports drink and after consuming 2 ounces the patient had two small episodes of emesis which resembled the sports drink.

At that time there became a concern that food impaction was responsible for the patient's symptoms rather than an allergic reaction. An esophagram was ordered which revealed a retained food bolus within the distal esophagus with only a trace amount of contrast passing distally into the stomach. On endoscopy, there were signs of inflammation and biopsies revealed 45 eosinophils per high powered field. The patient was subsequently diagnosed with Eosinophilic Esophagitis. Patient consent was obtained to use this case for educational purposes.

Conclusion: This case highlights the necessity to maintain a broad differential diagnosis as it is easy to become swayed by other provider's assessments. It is also important to remember that food impaction can be the presenting symptom in Eosinophil Esophagitis, especially in a patient with atopy.

https://doi.org/10.32873/unmc.dc.gmerj.3.1.018

\section{Tremor as a Probable Adverse Drug Reaction to Levetiracetam: A Case Report} Navnika Gupta ${ }^{1}$, Mara Seier ${ }^{1}$, Aditya Vuppala ${ }^{1}$

${ }^{1}$ University of Nebraska Medical Center, Department of Neurological Sciences

Mentor: Aditya Vuppala

Program: Neurological Sciences

Type: Case Report

Background: Levetiracetam (LEV) is used for treatment of epilepsy and movement disorders. Its common adverse drug reactions (ADRs) are neuropsychiatric symptoms and drowsiness. We report a case of LEVassociated head and hand tremors.

Case: A sixty-seven-year-old right-handed woman presented for seizure evaluation. She had febrile seizures as a child and was seizure-free until the age of twenty-eight when she had convulsive seizures, staring spells and auras for which phenytoin and primidone were started. She was event-free until the age of sixty-six when she started having frequent auras. LEV was started and titrated to the maximum recommended dose. She reported head and hand tremors after LEV initiation and denied prior tremor history. Her tremors improved but persisted after lowering the LEV dose.

She underwent continuous videoelectroencephalogram (EEG) monitoring 